\title{
Multi-cell Multi-port Bidirectional Flyback based on GaN devices
}

\author{
Ander Avila ${ }^{a}$, Asier Garcia-Bediaga ${ }^{a}$, Alberto Rodriguez ${ }^{b},{\text { Luis } \text { Mir }^{a}, \text { Alejandro Rujas }}^{a}$ \\ a) Power Electronics Area, IKERLAN Technological Research Centre, Arrasate-Mondragón, Spain, aavila@ikerlan.es \\ ${ }^{b)}$ Power Supply Systems Group (SEA), Universidad de Oviedo, Gijón, Spain, rodriguezalberto@uniovi.es
}

\begin{abstract}
This paper proposes the novel Multi-cell Multi-port Bidirectional Flyback (M2BF), which is suitable for applications with high-controllability requirement. Moreover, control strategy of the proposed converter and design considerations are analyzed, identifying the most differential characteristics. The main advantage of M2BF is the possibility of configuring the number of connected cells according to the specifications of the system. Besides, an independent control of each cell is proposed with a bidirectional power flow. The assembled experimental prototype is also presented, in order to validate the proposed concept.

Index Terms-Isolated converter, Multi-cell, Multi-port, Gallium Nitride
\end{abstract}

\section{INTRODUCTION}

Multi-cell topologies are commonly defined as converter systems formed with two or more subsystems that are connected in one of the following configurations: inputseries output-parallel, input-series output-series, input-parallel output-series or input-parallel output-parallel. Moreover, systems with two or more input or/and outputs are known as multi-port systems with different possibilities: single-input multiple-output, multiple input single-output and multipleinput multiple-output.

Multi-cell Multi-port (MCMP) systems have been established primarily in medium- to high-voltage high-power applications [1], [2]. However, in recent years, the versatility of MCMP architecture has also been demonstrated for lower power range, such as DC Power Distribution Systems (DCPDS) [3] or distributed Energy Storage Systems (ESS) [4], among others. These applications require multiple sources with a full control of delivered power, providing isolation in some cases.

In this context the novel Multi-cell Multi-port Bidirectional Flyback (M2BF) is proposed, allowing either dc or ac sources as inputs-outputs. In this work, only dc-dc configuration is analyzed. This architecture enables a bidirectional power flow with an individual control of each cell due to four quadrant switches Fig. 1(a). Besides, M2BF adds the possibility of configuring the number of connected cells according to system requirements. This results on a very versatile and configurable (a)

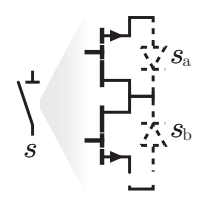

(b)
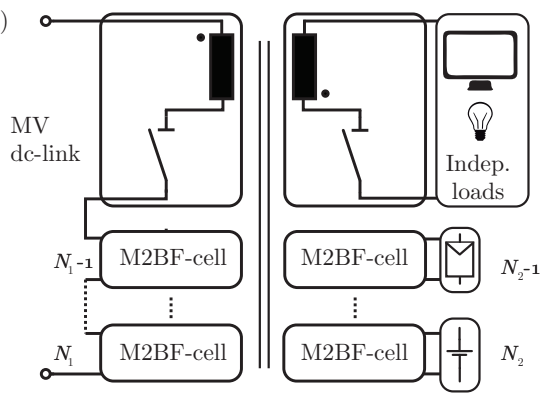

(c)
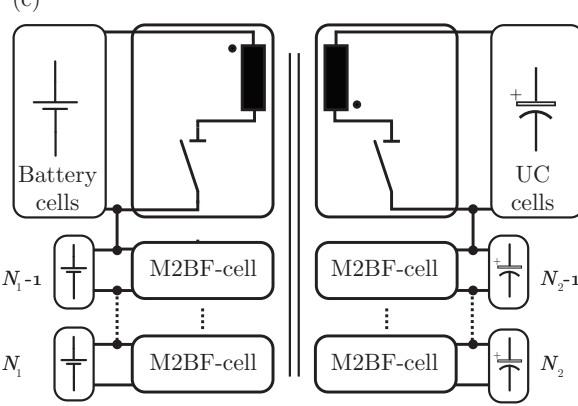

Fig. 1: M2BF potential dc-dc applications: (a) GaN-based bidirectional switch, (b) DC-PDS with Medium Voltage (MV) primary side and independent secondary sides and (c) hybrid ESS based on battery and ultra capacitors (UC) cells.

system, being suitable for many different applications, as it is shown in Fig. 1 for different dc-dc solutions.

In addition, semiconductors with better performance can be used because the total power is fractioned between the number of cells. In this context, Gallium Nitride $(\mathrm{GaN})$ devices appear as an interesting solution, mainly due to low conduction losses and high switching performance [5]. The use of Low Voltage (LV) GaN devices $(<400 \mathrm{~V})$ for MCMP systems clearly improves the performance of the converter [6], [7]. Besides, it has to be noted that GaN devices present remarkable benefits for MCMP systems, as a consequence of low gate driver requirements [8]. That is an important factor 


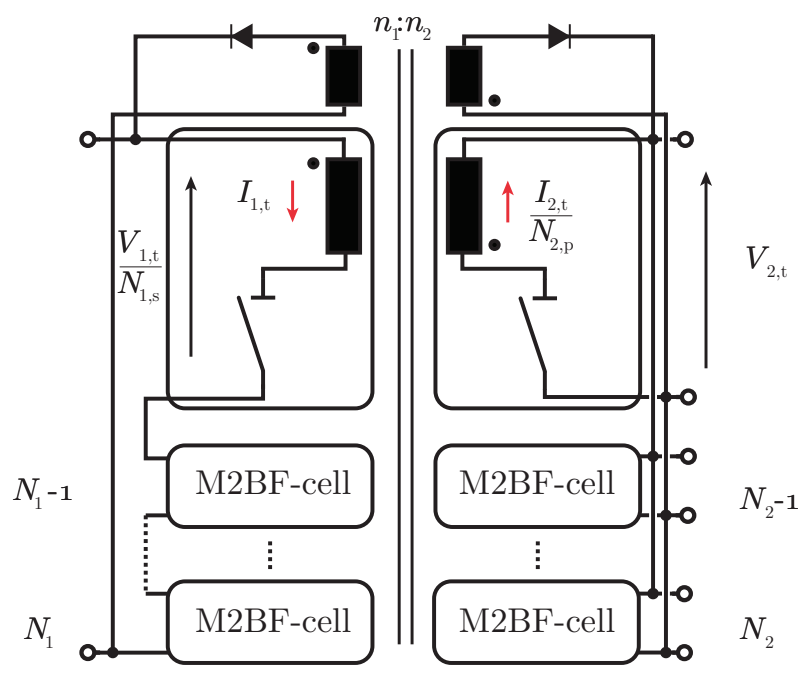

Fig. 2: M2BF concept configured with input-series and output-parallel cells.

due to the higher number of devices used on MCMP systems.

This work is organized as follows. Section II describes the novel M2BF concept. Operation principles and the most the most relevant design aspects are described in comparison with a conventional flyback. Then, in Section III the control strategy and key waveforms of the system are analyzed, along with a performance analysis of the M2BF based on $\mathrm{GaN}$ devices. Moreover, the developed GaN-based M2BF converter prototype is presented in Section IV. Finally, Section V draws some conclusions about the benefits and limitations of this novel configuration.

\section{Multi-CELl Multi-PORT BidiReCtional FlybaCK CONCEPT}

The proposed multi-cell flyback configuration has a modular structure with $N_{1}$ primary and $N_{2}$ secondary side number of cells, as it is depicted in Fig. 2. Four quadrant switch is used as main switch, in order to connect/disconnect cells in accordance to system requirements. In addition, two auxiliary windings are connected with diodes to primary and secondary sides, as it is depicted in Fig. 2. These windings do not operate at normal operating conditions. These auxiliary windings only operate in case of system-failure providing a discharging path for the current.

One of the main drawbacks of a flyback is that it requires semiconductors with higher voltage and current capability than other conventional converters. This is a consequence of induced voltages and currents [9]. Multi-cell systems results on either distribute the voltage between $N_{\mathrm{s}}$ series-connected cells or share the current along $N_{\mathrm{p}}$ parallel-connected cells. The proposed architecture allows to configure cells in order to reduce maximum voltage (1) and current (2) requirements of primary or secondary sides.

$$
\begin{gathered}
V_{\mathrm{a}, \mathrm{i}} \approx \frac{V_{\mathrm{a}, \mathrm{t}}}{N_{1, \mathrm{~s}}}+\frac{V_{2, \mathrm{t}} \cdot n}{N_{2, \mathrm{~s}}}, \\
V_{\mathrm{b}, \mathrm{i}} \approx \frac{V_{\mathrm{a}, \mathrm{t}}}{N_{1, \mathrm{~s}} \cdot n}+\frac{V_{2, \mathrm{t}}}{N_{2, \mathrm{~s}}} \\
I_{\mathrm{a}, \mathrm{i}} \approx \frac{I_{1, \mathrm{t}}}{N_{1, \mathrm{p}}}, \\
I_{\mathrm{b}, \mathrm{i}} \approx \frac{I_{2, \mathrm{t}}}{N_{2, \mathrm{p}}}
\end{gathered}
$$

where $n$ is the transformer ratio $\left(n_{1} / n_{2}\right)$ and $V_{1, \mathrm{t}}, I_{1, \mathrm{t}}$ and $V_{2, \mathrm{t}}, I_{2, \mathrm{t}}$ are the total voltage and current of primary and secondary sides, respectively. Figure 2 presents an input-series output-parallel configuration reducing the voltage requirement of primary side cells and the current of secondary side cells.

\section{A. Operation principles}

The power delivery of M2BF is similar to a conventional flyback, but considering the number of connected cells and a bidirectional power flow control. The power delivery can be divided into two intervals: magnetizing and demagnetizing process. Assuming a current flowing from primary to secondary side, the magnetizing process begins with the turn-on of primary side main switch $s_{1, \mathrm{i}}$, storing the energy on the transformer. Then, when turning-off $s_{1, \mathrm{i}}$, the energy stored in the transformer is discharged on the secondary side, as it is shown in Fig. 3(a) with two connected cells on each side.

On the contrary, considering a current flowing from secondary to primary side, magnetizing period is performed on the secondary side while demagnetizing occurs at primary side [see Fig. 3(b)].

Furthermore, the magnetic flux of the transformer $\left(\phi_{\mathrm{m}}\right)$ is proportional to the sum of primary and secondary side currents. Thus, in the M2BF, $\phi_{\mathrm{m}}$ changes according to the sum of the current generated on each cell (3). Figure 3(b) shows how $\phi_{\mathrm{m}}$ is decreased when enabling only one cell of each side in comparison with the configuration presented in Fig. 3(a).

$$
\phi_{\mathrm{m}}=\left(\sum_{i=1}^{N_{1}} \frac{i_{1, \mathrm{i}}}{n_{1}}+\sum_{i=1}^{N_{2}} \frac{i_{2, \mathrm{i}}}{n_{2}}\right) \cdot L_{\mathrm{m}}
$$

being $L_{\mathrm{m}}$ the magnetizing inductance.

\section{B. Bidirectional switch}

Four quadrant flyback is proposed, based on two anti-series semiconductors for primary and secondary sides. Fig. 4(a) shows how $s_{\mathrm{b} 1,2}$ blocks the current on the primary side $\left(i_{1,2}=0\right)$ and $s_{\mathrm{b} 2,1}$ on the secondary side $\left(i_{2,1}=0\right)$, when the current is flowing from primary to secondary side. Conversely, considering a current flowing from secondary to primary side, $i_{2,1}$ yields to zero due to the blocking capability of $s_{\mathrm{a} 2,1}$, while the same is true for $s_{\mathrm{a} 1,2}$ device on the primary side 


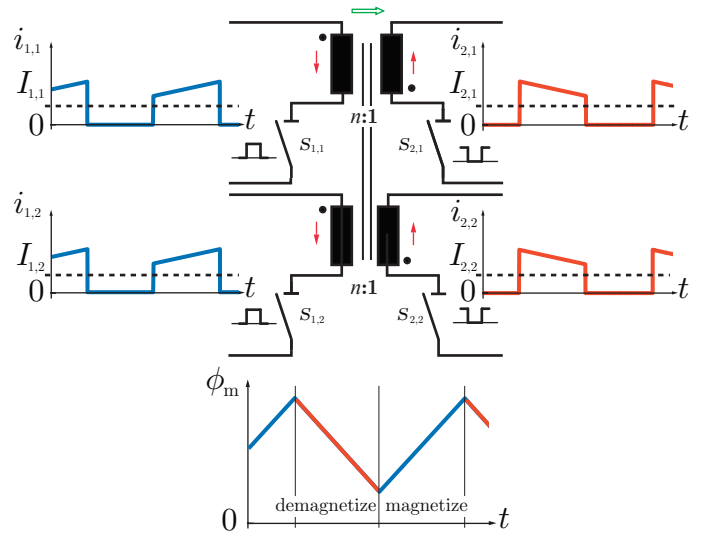

(a)

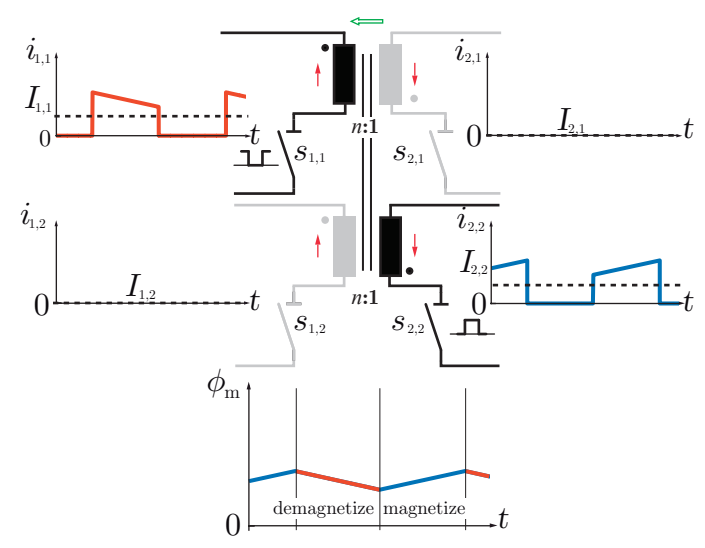

(b)

Fig. 3: M2BF concept along with magnetic flux $\left(\phi_{\mathrm{m}}\right)$, primary $\left(i_{1, \mathrm{i}}\right)$ and secondary $\left(i_{2, \mathrm{i}}\right)$ side currents for different configurations: (a) primary to secondary power flow with two connected cells on each side and (b) secondary to primary flow with one active cell on each side.

[see Fig. 4(b)]. Hence, bidirectional voltage and/or current conduction and blocking capability is achieved.

However, the implementation of bidirectional switch results on higher number of semiconductors than for a conventional flyback and consequently higher conduction losses. Therefore, devices with low conduction resistance, such as GaN semiconductors, are presented as the most suitable solution. Besides, in near future, monolithically integrated bidirectional GaN devices will overcome this limitation with significantly lower conduction losses [10]. The lateral structure of GaN devices allows to include a second gate near the drain, achieving a bidirectional power semiconductor without an excessive increase of the conduction resistance [11].

\section{Design considerations}

Regarding the sizing of converter components, it is similar to a conventional flyback, being the main difference related to the multi-winding transformer. Multi-winding transformer

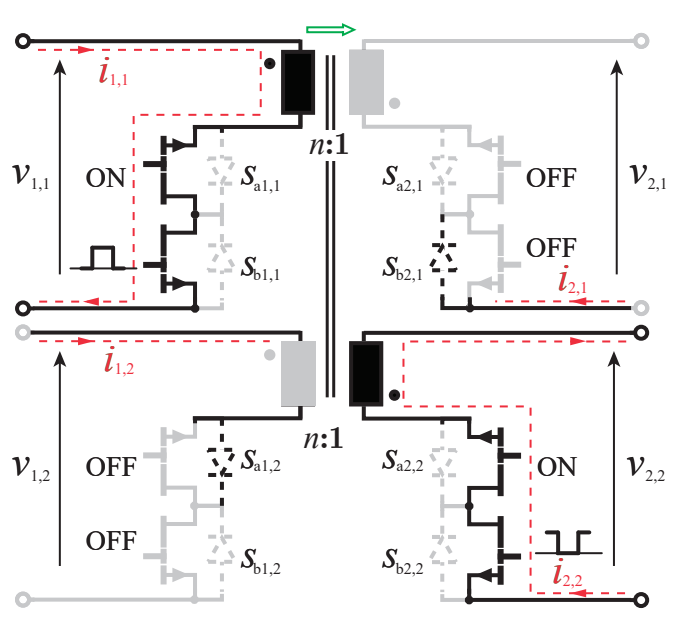

(a)

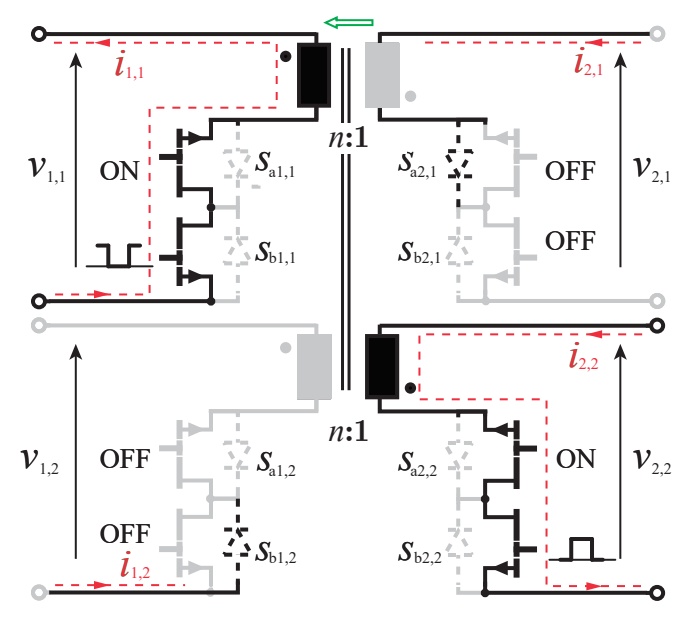

(b)

Fig. 4: Bidirectional switches based on GaN devices with "body diode" (dashed lines): (a) current flowing from primary to secondary side and (b) current flowing from secondary to primary side.

with $N_{1}+N_{2}+2$ number of windings is required. The magnetizing inductance is defined with (4) for a certain current ripple $\Delta i$ and switching frequency $f_{\mathrm{s}}$ [9]. The $\Delta i$ defines the operation mode of a flyback. In this case, a continuous conduction mode is considered, avoiding excessive conduction losses produced by operation modes with high current ripple.

$$
L_{\mathrm{m}}=\frac{V_{\mathrm{in}} \cdot \delta}{2 \cdot f_{\mathrm{s}} \cdot \Delta i \cdot I_{\mathrm{Lm}}}
$$

being $\delta$ the voltage conversion ratio and $I_{\mathrm{Lm}}$ the magnetizing current defined as follows:

$$
\begin{gathered}
\delta=\frac{n \cdot V_{\mathrm{o}, \mathrm{i}}}{n \cdot V_{\mathrm{o}, \mathrm{i}}+V_{\mathrm{in}, \mathrm{i}}} \\
I_{\mathrm{Lm}}=\sum_{i=1}^{N_{1}} \frac{P_{\mathrm{o}, \mathrm{i}}}{\eta \cdot V_{\mathrm{in}, \mathrm{i}}}+\sum_{i=1}^{N_{2}} \frac{I_{\mathrm{o}, \mathrm{i}}}{n}
\end{gathered}
$$


being $n$ the transformer conversion ratio, $P_{\mathrm{o}, \mathrm{i}}$ output power, $V_{\mathrm{o}, \mathrm{i}}$ output voltage and $V_{\mathrm{in}, \mathrm{i}}$ input voltage of cell $i$. The maximum current $I_{\mathrm{Lm}}$ is a result of the sum of all cells currents.

Then, considering the worst case scenario, i.e. the minimum $\delta$ and the peak magnetizing current, $L_{\mathrm{m}}$ is defined. Moreover, the transformer is designed to have a reduced leakage inductance $L_{\mathrm{lk}}\left(3-5 \% \cdot L_{\mathrm{m}}\right)$ in order to reduce the overvoltage generated on the main switch.

Then, the equivalent inductance matrix is defined with (7).

$$
\left[\begin{array}{cccc}
L_{1 \mathrm{p}, 1 \mathrm{p}} & L_{1 \mathrm{p}, 1 \mathrm{~s}} & \ldots & L_{1 \mathrm{p}, i \mathrm{~s}} \\
L_{1 \mathrm{~s}, 1 \mathrm{p}} & L_{1 \mathrm{~s}, 1 \mathrm{~s}} & \ldots & L_{1 \mathrm{~s}, i \mathrm{p}} \\
\vdots & \vdots & \vdots & \vdots \\
L_{i \mathrm{~s}, 1 \mathrm{p}} & L_{i \mathrm{p}, 1 \mathrm{~s}} & \ldots & L_{i \mathrm{~s}, i \mathrm{~s}}
\end{array}\right]
$$

where every coil of multi-winding transformer is formed by its own inductance $\left(L_{1 \mathrm{p}, 1 \mathrm{p}}\right)$ and the mutual inductance between coils, e.g $L_{1 \mathrm{p}, 1 \mathrm{~s}}$ which corresponds to the mutual inductance between first primary and first secondary coils.

The multi-winding coils are distributed in a symmetrical way, in order to reduce the leakage inductance of each module. Besides, primary and secondary windings are interleaved, as it is shown in Fig. 5 for six winding transformer: four main coils and two auxiliary. The diameter of the wire of auxiliary windings is reduced as these coils only operate in case of system failure.

ETD-type core is selected dividing coils in high and low side, with auxiliary windings in the middle. With the aim of reducing leakage inductance, i.e. achieving a high coupling between main coils, first primary, first secondary, second primary and second secondary, sequence is repeated from high to low side of the transformer. However, the coupling between main coils and auxiliary windings is not as good as between main coils. In this configuration, as auxiliary coils only operate in case of system failure.

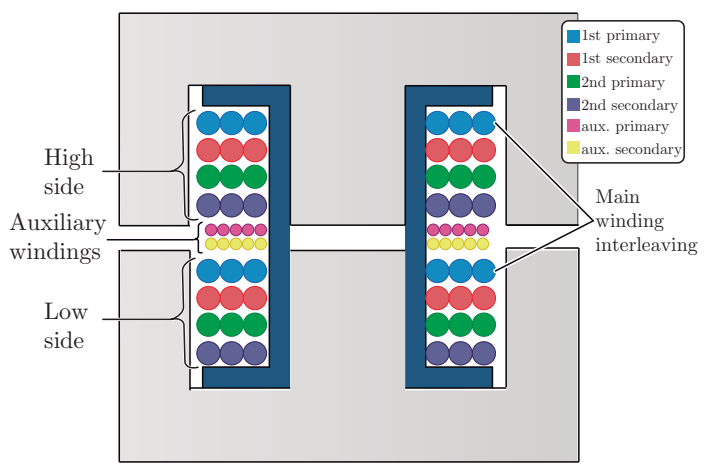

Fig. 5: Flyback transformer winding distribution for a reduced leakage inductance of the M2BF transformer.
In addtion, flyback cells are operated with an active clamp circuit, in order to reduce switching losses. Active clamp is implemented in both sides due to the bidirectional operation of the converter. Considering the leakage inductance, clamp capacitor $C_{\mathrm{r}}$ is selected to be in resonance with $L_{\mathrm{lk}}$ at a switching frequency $f_{\mathrm{s}}(8)$. Furthermore, devices output capacitances are not considered, as $\mathrm{GaN}$ devices present negligible $C_{\mathrm{oss}}$ in comparison to $C_{\mathrm{r}}$.

$$
C_{\mathrm{r}}=\frac{1}{\left(2 \cdot \pi \cdot f_{\mathrm{s}}\right)^{2} \cdot L_{\mathrm{lk}}} .
$$

\section{GAN-BASED M2BF DESIGN}

In this section the control strategy is described along with a performance evaluation of the performance of GaN-based $\mathrm{M} 2 \mathrm{BF}$ for the specifications of Table I. A unity relation between primary and secondary side main coils is chosen. Nevertheless, auxiliary windings are designed with a transformer relation of $n / n_{\text {aux }}>1$, but close to the unity in order to avoid excessive induced overvoltage, in case of failure. Figure 6 shows a dc-dc M2BF with active clamp switches $\left(s_{\mathrm{c} 1, \mathrm{i}}, s_{\mathrm{c} 2, \mathrm{i}}\right)$ and clamping capacitors $\left(C_{\mathrm{r}}\right)$. The same switches configuration is implemented in both sides as the power can be delivered in both directions.

\section{A. Control Strategy}

Figure 7 shows the implemented control strategy. Current control is performed measuring current $\left(i_{1, \mathrm{i}}, i_{2, \mathrm{i}}\right)$ of each cell. In addition, peak current detector is implemented by hardware and then calibrated to obtain the relation between peak current and delivered current. Moreover, the voltage of each cell is measured, in order to obtain the power of every cell.

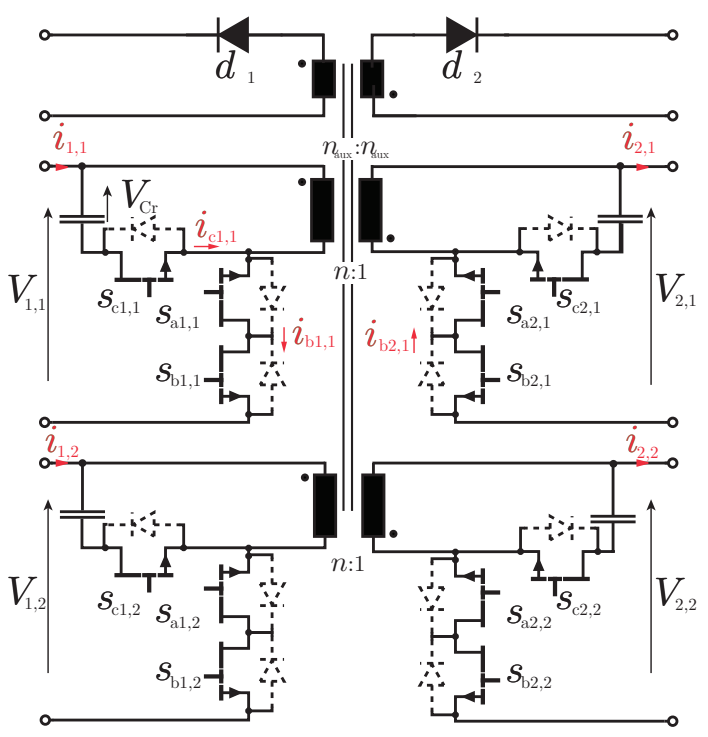

Fig. 6: M2BF converter based on GaN devices, with two primary and secondary side cells and active clamp. 
TABLE I: M2BF cell electrical specifications.

\begin{tabular}{lcc}
\hline Description & Value & Unit \\
\hline \hline Input voltage $-V_{1, \mathrm{i}}$ & 24 & $\mathrm{~V}$ \\
Output voltage $-V_{2, \mathrm{i}}$ & 24 & $\mathrm{~V}$ \\
Output current $-I_{2, \mathrm{i}}$ & 5 & $\mathrm{~A}$ \\
Current ripple $-\Delta i$ & 0.2 & \\
Transformer ratio - $n$ & 1 & \\
Transformer auxiliary ratio $-n_{\mathrm{aux}}$ & 1.2 & \\
Switching frequency - $f_{\mathrm{s}}$ & 300 & $\mathrm{kHz}$ \\
\hline Semiconductor characteristics & Value & $\mathrm{Unit}$ \\
\hline Case-to-heat-sink resistance $R_{t h, c-h}$ & 4.5 & ${ }^{\circ} \mathrm{C} / \mathrm{W}$ \\
Junction-to-case resistance $R_{t h, j-c}$ & 0.3 & ${ }^{\circ} \mathrm{C} / \mathrm{W}$ \\
\hline
\end{tabular}

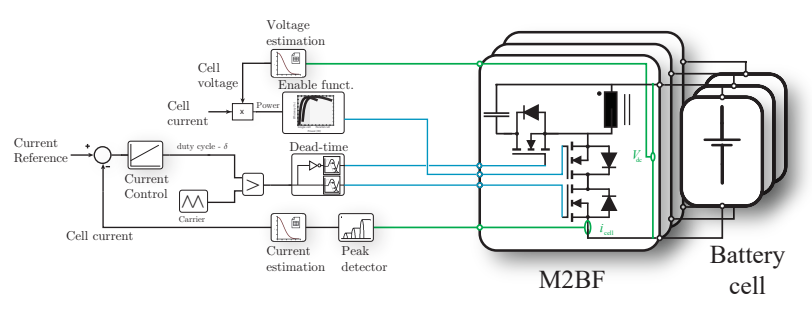

Fig. 7: M2BF converter control scheme.

Control signals of switches are enabled or not depending on the power flow and the enable function. In this first control strategy approach, an enable function that results on the highest efficiency is implemented. Thus, the number of connected cells is selected in terms of the required power. The impact of number of cells on the system efficiency is analyzed hereafter.

It must be noted that the enable function can be defined for different system parameters. Indeed, multiple loads and sources can be controlled independently, as for DC-PDS systems [see Fig. ??(a)]. Moreover, in the case of ESS operating with series connected cells [see Fig. ??(b)], enable function is designed in terms of the State of charge ( $\mathrm{SoC}$ ), being possible to perform an integrated active balancing of cells, as in the active equalizer presented in [12].

\section{B. Key Waveforms}

Figure 8(a) shows the voltage that $C_{\mathrm{r}}$ has to withstand and the leakage current $\left(i_{\mathrm{Lk}}\right)$ of the primary side. Negative leakage current is allowed on the primary side, due to clamping switches.

Moreover, considering primary to secondary power flow, switching transitions of power switches are analyzed in Fig. 8(b). Zero Voltage Switching (ZVS) of primary switch $s_{\mathrm{a} 1,1}$ is achieved due to active clamp. Besides, Fig. 8(b) shows the switches control signals considering a power flow from primary to secondary side and enabling only one cell on each side.
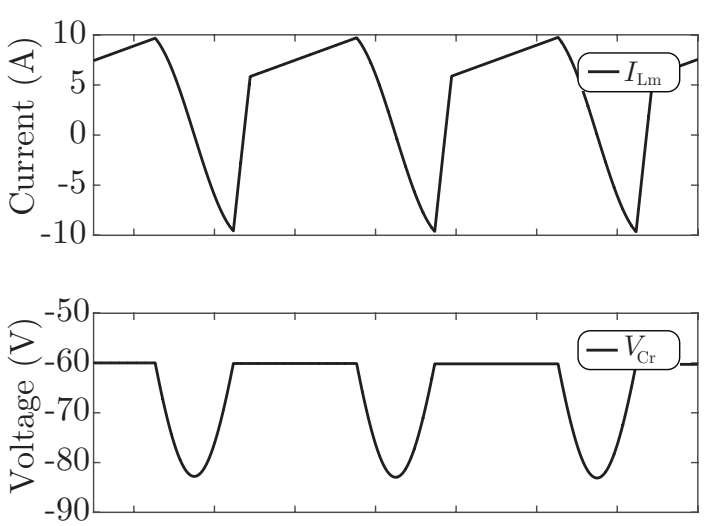

(a)
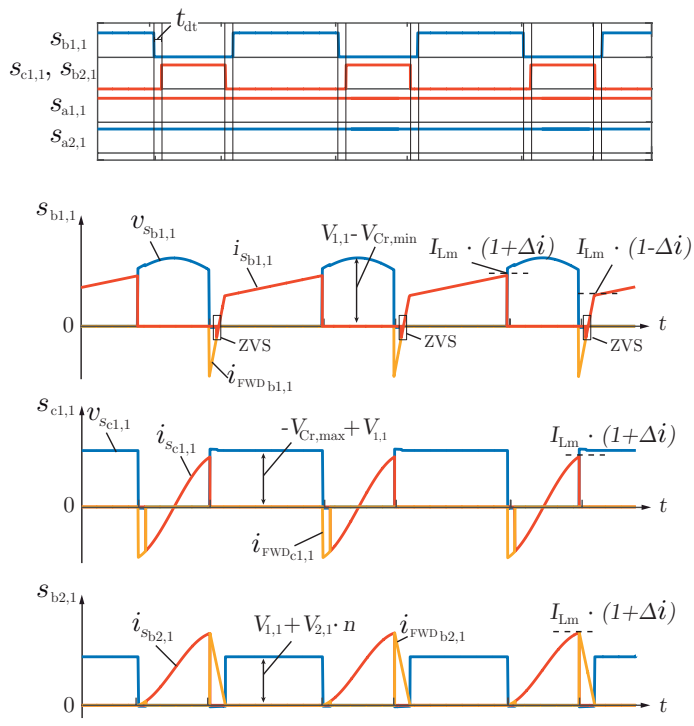

(b)

Fig. 8: Power switches transitions of M2BF, including its "body diodes" conduction instances.

Primary main switch $s_{\mathrm{b} 1,1}$ is switching with a duty $\delta$ while switch $s_{\mathrm{b} 2,1}$ and clamping switch $s_{\mathrm{c} 1,1}$ toggles complementary to $s_{\mathrm{b} 1,1}$ with a defined dead-time $t_{\mathrm{dt}}$. A minimum dead-time of $50 \mathrm{~ns}$ is defined, considering the analysis presented in [13], characteristics of the selected low-voltage GaN devices [14] and driver characteristics. Besides, anti-series switches $s_{\mathrm{a} 1,1}$ and $s_{\mathrm{a} 2,1}$ are continuously conducting according to enable function due to the free-wheeling conduction instances. The same control sequence of anti-series switches is applied if the current is flowing from secondary to primary side, i.e. switching with $s_{\mathrm{b} 2, \mathrm{i}}$ and continuously with $s_{\mathrm{a} 2, \mathrm{i}}$. 


\section{Performance Evaluation}

Figure 8 shows switching waveforms of each switch that conform the M2BF. Soft-switching operation is achieved operating with a switching frequency near to resonance frequency $f_{\mathrm{r}}$. ZVS operation of main switches of primary and secondary sides is achieved along with soft turn-on of clamping switches. In addition, conduction instances of the "body diode", have to be also considered.

Figure 9 shows the power losses distribution of each switch. Assuming a power flow from primary to secondary side, primary side presents main switch, auxiliary switch and clamp switch losses. On the contrary, secondary side cell only presents main switch and auxiliary switch losses. The use of active clamp reduces switching losses relevance, being negligible even for $300 \mathrm{kHz}$, as a consequence of reduced turnoff losses of GaN transistors.

It is worth to pointing out that the use of two anti-series device as main switch increases total conduction power losses. The use of GaN devices in this topology allows to reduce con-

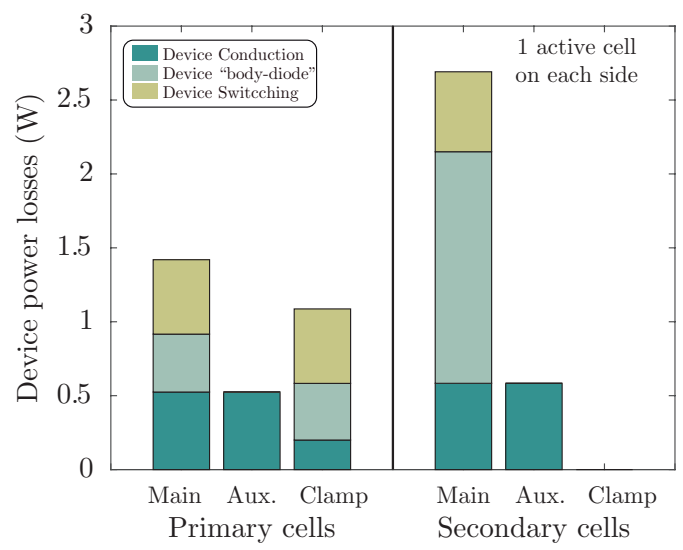

(a)

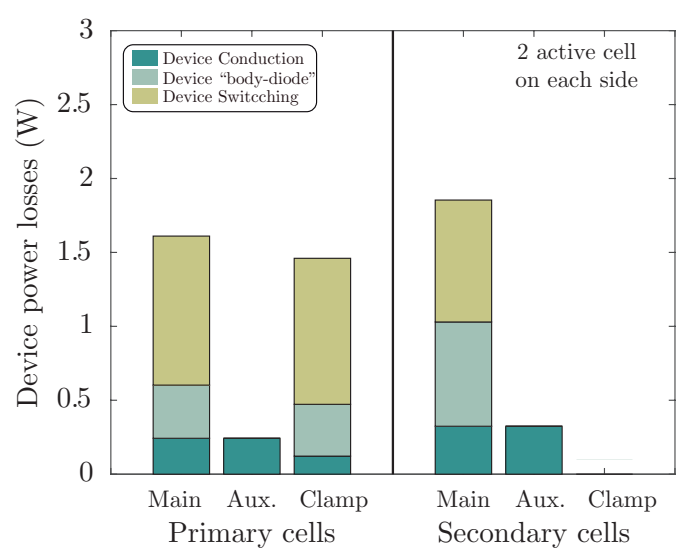

(b)

Fig. 9: M2BF cell power losses distribution based on GaN devices $(120 \mathrm{~W})$ : (a) connecting one cell on each side and (b) connecting two cells on each side

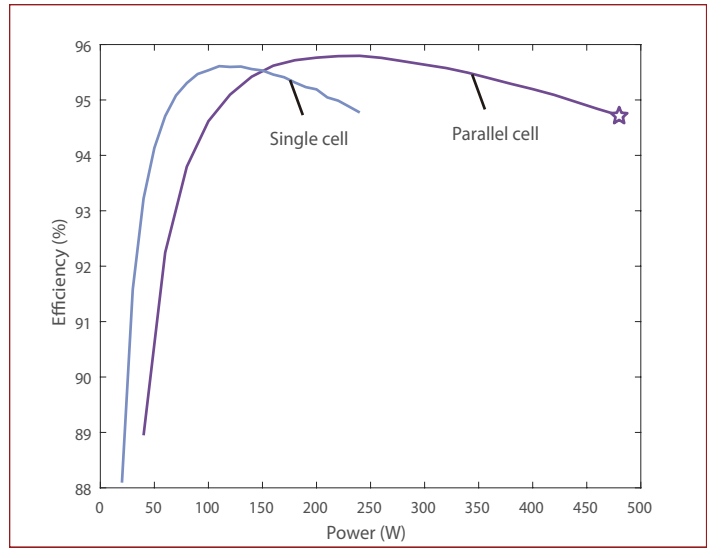

Fig. 10: Performance evaluation of the M2BF efficiency for different cell configurations.

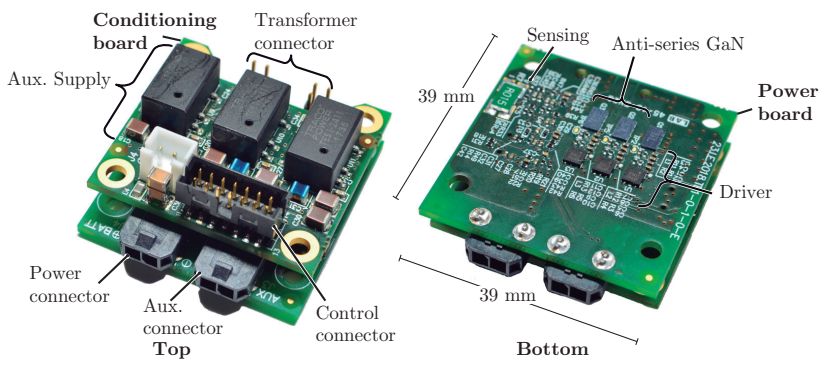

Fig. 11: GaN-based M2BF power cell consisting of power and conditioning board.

duction losses and switching losses. However, dead-time losses of synchronous devices needs to be specially considered, as an important part of synchronous device losses.

In addition, Fig. 9 compares power losses distribution of a M2BF operating with single cell and two cells, for a primary to secondary power flow of $120 \mathrm{~W}$. Comparing both variants, conduction and dead-time losses are reduced while switching losses increase when considering two connected cells. Then, depending on the impact of conduction, dead-time and switching losses, the optimal number of connected cells will be different.

The performance of the proposed architecture is evaluated for the whole operation range, for different cell configurations. Figure 10 shows how depending on the demanded power the use of single or multiple cells presents higher efficiency.

\section{EXPERIMENTAL PROTOTYPE}

This section presents the power cells of the GaN-based M2BF. The power cell is composed of a power board and a conditioning board, as it is depicted in Fig. 11. The power converter is based on $\mathrm{LV} \mathrm{GaN} \mathrm{devices} \mathrm{resulting} \mathrm{in} \mathrm{a} \mathrm{power}$ module with reduced size.

The presented power module is configured to operate as a synchronous buck converter, in order to validate the per- 


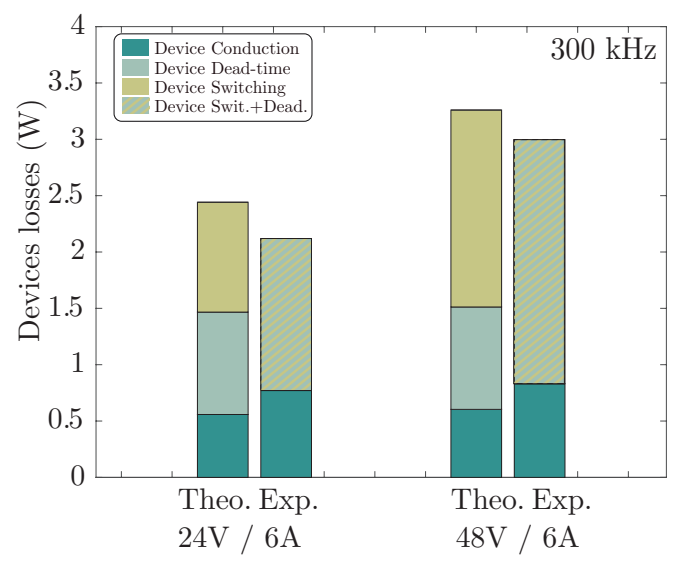

Fig. 13: Experimental validation of $\mathrm{LV} \mathrm{GaN}$ devices performance working at high-switching frequency in hard-switching mode $(300 \mathrm{kHz} / 6 \mathrm{~A})$.

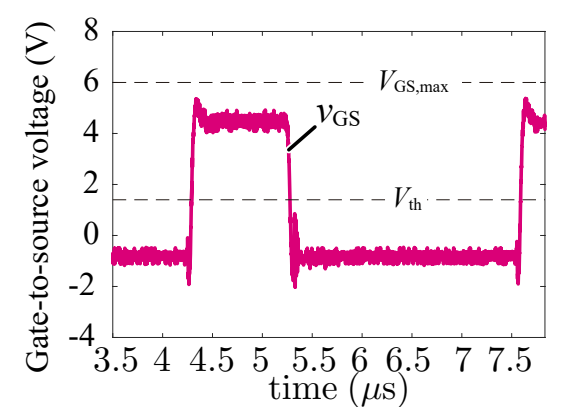

(a)

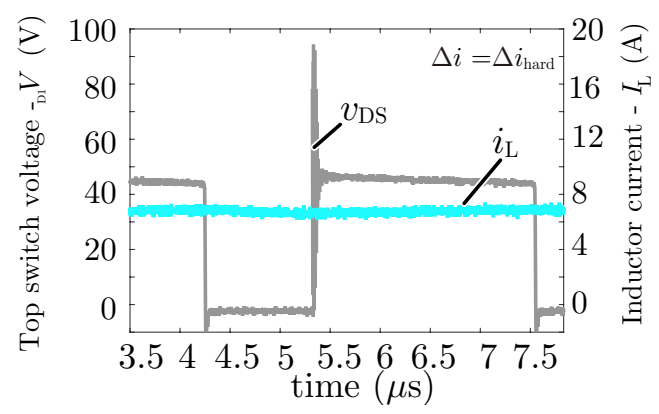

(b)

Fig. 12: Experimental validation of $\mathrm{LV}$ GaN devices performance working at high-switching frequency in hard-switching mode $(300 \mathrm{kHz} / 6 \mathrm{~A})$.

formance of $\mathrm{LV} \mathrm{GaN}$ devices operating at high-switching frequency.

The buck converter operates in hard-switching mode, with reduced current ripple, as it is depicted in Fig. 12(b). Experimental measurements of power losses are presented in Fig. 13, achieving a good agreement between theoretical and experimental measurements. Low switching losses are achieved, even operating in hard-switching mode. Moreover, although anti-series switch is implemented, the use of $\mathrm{GaN}$ devices results on low conduction losses. However, dead-time losses impact is higher, due to high-switching frequency. Therefore, it is crucial to reduce dead-time conduction instances. Once the performance of the power module has been evaluated working as buck converter, the performance working in M2BF configuration will be presented in future works.

\section{Conclusions}

This paper presents a novel bidirectional isolated architecture $(\mathrm{M} 2 \mathrm{BF})$ with high versatility for near future applications. The proposed M2BF includes a four quadrant switch, being possible to configure converter to the system requirements. Therefore, an independent control of each cell can be performed, increasing the controllability of the system. Besides, the multi-cell multi-port configuration allows the use of highperformance devices for higher power range. High-efficiency is achieved over the wide output load, adapting the number of connected cells to the required output power.

\section{REFERENCES}

[1] S. Inoue and H. Akagi, "A Bidirectional Isolated DC-DC Converter as a Core Circuit of the Next-Generation Medium-Voltage Power Conversion System," IEEE Transactions on Power Electronics, vol. 22, no. 2, pp. 535-542, Mar. 2007.

[2] D. Dujic, F. Kieferndorf, F. Canales, and U. Drofenik, "Power electronic traction transformer technology," in International Power Electronics and Motion Control Conference, 2012.

[3] D. Boroyevich, I. Cvetkovi, D. Dong, R. Burgos, F. Wang, and F. Lee, "Future electronic power distribution systems a contemplative view," in International Conference on Optimization of Electrical and Electronic Equipment, 2010

[4] J. Cao and A. Emadi, "A new battery/ultracapacitor hybrid energy storage system for electric, hybrid, and plug-in hybrid electric vehicles," IEEE Transactions on Power Electronics, vol. 27, no. 1, pp. 122-132, Jan. 2012

[5] A. Avila, A. Garcia-Bediaga, A. Rodriguez, L. Mir, and A. Rujas, "Analysis of Optimal Operation Conditions for GaN-based Power Converters," in IEEE Energy Conversion Congress and Exposition (ECCE), 2018.

[6] M. Antivachis, M. Kasper, D. Bortis, and J. W. Kolar, "Analysis of capacitive power transfer GaN ISOP multi-cell DC/DC converter systems for single-phase telecom power supply modules," in IEEE Industrial Electronics Society IECON, 2016.

[7] M. Guacci, D. Bortis, and J. W. Kolar, "High-Efficiency WeightOptimized Fault-Tolerant Modular Multi-Cell Three-Phase GaN Inverter for Next Generation Aerospace Applications," in Energy Conversion Congress and Exposition (ECCE), 2018.

[8] J. Millan, P. Godignon, X. Perpina, A. Perez-Tomas, and J. Rebollo, "A Survey of Wide Bandgap Power Semiconductor Devices," IEEE Transactions on Power Electronics, vol. 29, no. 5, pp. 2155-2163, May 2014.

[9] X. Huang, J. Feng, W. Du, F. C. Lee, and Q. Li, "Design consideration of $\mathrm{MHz}$ active clamp flyback converter with $\mathrm{GaN}$ devices for low power adapter application," in Applied Power Electronics Conference and Exposition (APEC), 2016.

[10] T. Morita, M. Yanagihara, H. Ishida, M. Hikita, K. Kaibara, H. Matsuo, Y. Uemoto, T. Ueda, T. Tanaka, and D. Ueda, "650 V 3.1 mOhmcm $2 \mathrm{GaN}$-based monolithic bidirectional switch using normallyoff gate injection transistor," in IEEE International Electron Devices Meeting, 2007.

[11] C. Kuring, O. Hilt, J. Bcker, M. Wolf, S. Dieckerhoff, and J. Wrfl, "Novel monolithically integrated bidirectional GaN HEMT," in Energy Conversion Congress and Exposition (ECCE), 2018. 
[12] T. Mizuno, T. Inoue, K. Iwasawa, and H. Koizumi, "A voltage equalizer using flyback converter with active clamp," in IEEE Asia Pacific Conference on Circuits and Systems, 2012.

[13] R. Xie, H. Wang, G. Tang, X. Yang, and K. J. Chen, "An analytical model for false turn-on evaluation of GaN transistor in bridge-leg con- figuration," IEEE Energy Conversion Congress and Exposition (ECCE), 2016.

[14] EPC "EPC2034

Enhancement Mode Power Transistor," 2019. [Online]. Available: https://epcco.com/epc/Portals/0/epc/documents/datasheets/EPC2034_datasheet.pdf 